\title{
AVALIAÇÃO DOS EFEITOS POTENCIAIS DOS ÁCIDOS GRAXOS SATURADOS E INSATURADOS NA CAPACIDADE PROLIFERATIVA DE CÉLULAS HEPÁTICAS
}

\author{
Victoria A. Cardoso*, Thaís de Fante, Laís Angélica de Paula Simino, Adriana Souza Torsoni.
}

\section{Resumo}

A prevalência de obesidade mundial é crescente e, junto a ela, o desenvolvimento de doenças hepáticas. $O$ tratamento dessas doenças em estágio avançado pode trazer riscos, pois muitas vezes a única opção é a ressecção do órgão. Dessa forma, o estudo avaliou o efeito do tratamento de hepatócitos com ácidos graxos, saturados e insaturados, sobre a indução de deposição de triacilgliceróis, parâmetros morfológicos e viabilidade celular.

Palavras-chave: Células hepáticas, ácidos graxos, DHGNA.

\section{Introdução}

Devido a mudanças nos padrões alimentares e sedentarismo, o mundo tem sido atingido por uma epidemia de sobrepeso e obesidade. Sabe-se que a obesidade é capaz de alterar o metabolismo lipídico hepático, ativar processos inflamatórios e aumentar a predisposição ao desenvolvimento da doença hepatica gordurosa não alcoólica (DHGNA), caracterizada pelo acúmulo de triacilgliceróis nos hepatócitos que podem gerar diversas complicações e que leva cerca de $20 \%$ dos casos a necessidade de ressecção cirúrgica. Como o fígado não apresenta a função de armazenamento de lipídeos, o acúmulo de gordura nesse órgão pode ser um fator prejudicial no processo regenerativo das células. $O$ presente projeto avaliou por Oil Red e ensaios de citotoxicidade, células hepáticas controles e tratadas com ácidos graxos saturados (palmitato), insaturados (palmitoléico) e ambos (mix de NEFA), analisando a deposição de gordura, morfologia e viabilidade celular, a fim de determinar a diferença entre os tipos de ácidos graxos na capacidade proliferativa das céulas in vitro, através de uma intervenção com IL-6, o principal mediador inflamatório pós hepatectomia parcial.

\section{Resultados e Discussão}

A fim de determinar a concentração e a toxicidade dos ácidos graxos, iniciamos os testes de padronização.
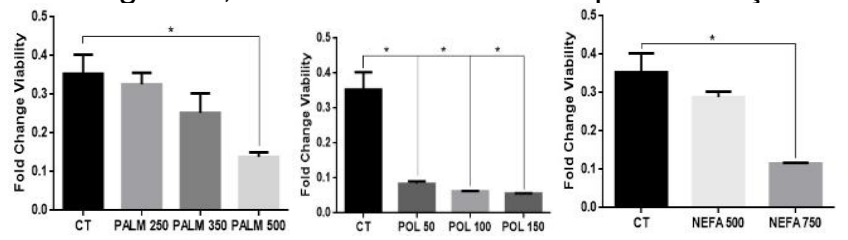

Figura 1. Ensaio colorimétrico de citotoxicidade (MTT). Todas as amostras são em relação ao controle (CT). A) Palmitato (Palm) 250 uM, 350 uM e 500 uM. B) Palmitoléico (Pol) 100uM, 150 uM e 250 uM. C) NEFA 500uM e 750 uM. n $=6$ wells para cada concentração. ${ }^{*} \mathrm{p}<0,05$.

Apresentaram uma melhor viabilidade celular as concentrações palmitato $350 \mathrm{uM}$, palmitoleico abaixo de 100 uM e NEFA 500 uM. O palmitoleico apresenta alta toxicidade em todas as concentrações (Figura 1). $\mathrm{Na}$ coloração com Oil Red, (Figura 2), observa-se o grupo tratado com palmitato e palmitoléico apresentam diferença na concentração lipídica antes e depois do tratamento com IL-6, que mimetiza o dano hepático causado pela cirurgia de hepatectomia parcial. A deposição de gordura hepática sem IL-6 é maior nas células tratadas com NEFA.
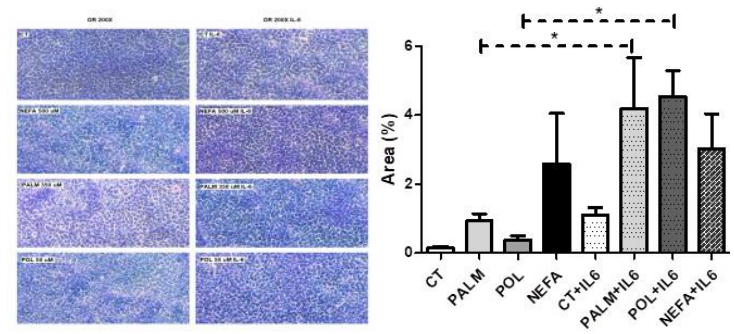

Figura 2. Coloração Oil Red: Palmitato 350 uM, Palmitoleico (POL) 50 uM e NEFA 500 uM, com e sem IL-6. Quantificação lipídica com o auxílio do software Image J. ANOVA one-way, $\mathrm{p}<0,05 . \mathrm{N}=3$ wells para cada grupo.

Observa-se uma atrofia nas células tratadas com palmitato em todas as concentrações definidas (Figura 3), o que leva à uma alteração morfológica das células do

fígado.
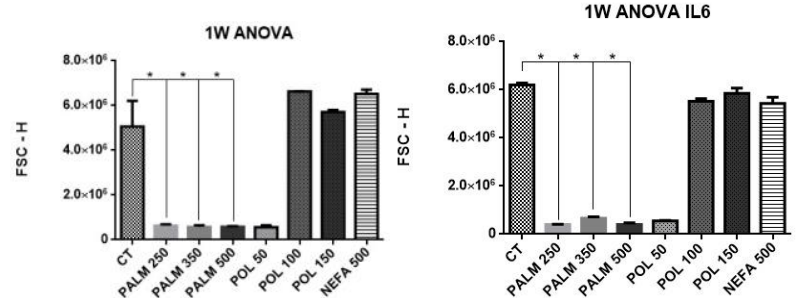

Figura 3. Quantificação da morfologia celular (FSC-H) de células com e sem tratamento com IL-6. Grupos: CT, Palm (250 uM, 350 uM e 500 uM), Pol (50 uM, 100 uM e 150 uM) e NEFA 500 uM. Imagens com auxílio do Software BD Accuri C6. $\mathrm{P}<0,05$. $\mathrm{N}=3$ wells para cada grupo.

\section{Conclusões}

Os achados do palmitato, palmitoléico e NEFA mostram que uma dieta equilibrada e saudável ainda é a melhor opção para o tratamento e prevenção da DHGNA.

\section{Agradecimentos}

A Adriana Torsoni, Thaís de Fante, Laís Simino e todos do LabDiMe. Apoio: PIBIC/CNPq.

Kennedy A, Martinez K, Chuang CC, LaPoint K, McIntosh M. Saturated fatty acid-mediated inflammation and insulin resistance in adipose tissue: mechanisms of action and implications. J Nutr. 2009; 139 (1):1-4

Liu TW, Heden TD, Matthew Morris et al., High-Fat Diet Alters Serum Fatty Acid Profiles in Obesity Prone Rats: Implications for In Vitro Studies. Lipids. 2015 Oct; 50(10):997-1008. 